Research Article

\title{
Effect of vitamin D on atorvastatin induced blood sugar changes in Wistar albino rats
}

\author{
R. Arunkumar*, Vinayak Meti, A. Ruckmani, Shobita Devi
}

\begin{abstract}
Department of Pharmacology, Chettinad Hospital and Research Institute, Kelambakkam, Tamil Nadu - 603 103, India

Received: 30 January 2014 Accepted: 25 February 2014

*Correspondence to:

Dr. R. Arunkumar, Email: arunrmbbs1978@, gmail.com

\section{(C) 2014 Arunkumar $\mathrm{R}$ et al.} This is an open-access article distributed under the terms of the Creative Commons Attribution Non-Commercial License, which permits unrestricted non-commercial use, distribution, and reproduction in any medium, provided the original work is properly cited.
\end{abstract}

\begin{abstract}
Background: Statins are hypocholestrolemic agents used in atherosclerotic vascular disorders. They act by inhibiting hepatic hypoxanthine methyl glutaryl CoA reductase enzyme. They are reported to cause hyperglycemia as an important adverse event. This study was conducted to investigate atorvastatin induced blood sugar changes in Wistar, albino, male rats and the influence of vitamin D on the blood sugar changes. Methods: Forty, 12 weeks old male, Wistar albino rats, were selected and randomly allocated to 5 groups of 8 animals, each. Animals in Group 1 were administered normal saline orally and served as controls. Group 2 and 3 received atorvastatin $2 \mathrm{mg}$ and $4 \mathrm{mg}$, respectively, orally. Group 4 and 5 received 200 IU of vitamin D along with $2 \mathrm{mg}$ and $4 \mathrm{mg}$ of atorvastatin respectively, orally. The drugs were administered once, every day for 3 months. Body weight and fasting blood sugar were estimated at baseline and at the end of every month for 3 months.

Results: In control animals (Group 1) and animals treated with atorvastatin along with vitamin D (Group 4 and 5), fasting blood sugar levels did not change significantly and the body weight increased. In animals treated with only atorvastatin (Group 2 and 3), fasting blood sugar was significantly increased and body weight did not change.

Conclusions: This study has demonstrated that chronic use of atorvastatin 2 and $4 \mathrm{mg}$ may lead to fasting hyperglycemia and it could be prevented by co-administration of 200 IU of vitamin D, in male Wistar albino rats. Randomized control studies in humans are further required to recommend routine use of vitamin D in patients receiving atorvastatin.
\end{abstract}

Keywords: Statins, Hyperglycemia, Blood sugar, Vitamin D, Atorvastatin

\section{INTRODUCTION}

Statins are hypocholestrolemic agents, used for primary and secondary prevention of mortality and morbidity in ischemic heart disease and other atherosclerotic vascular disorders. They include the drugs lovastatin, simvastatin, atorvastatin, rosuvastatin, fluvastatin, pravastatin and others. Thousands of patients are on long-term statin therapy across the world.

Statins act predominantly by inhibiting hypoxanthine methyl glutaryl CoA reductase enzyme in the liver. Statins also act through non-lipid lowering pleiotropic actions such as improvement of endothelial dysfunction, anti-oxidative properties, anti-inflammatory, anti-proliferative and antithrombotic effects and facilitation of neo-angiogenesis. These pleiotropic actions contribute to the use of statins in non-atherosclerotic disorders such as fibrosclerotic aortic stenosis, arterial hypertension, Alzheimer's dementia, rheumatic diseases (rheumatoid arthritis), sclerosis multiplex, prevention of sudden cardiac death, deep venous thrombosis, regression of left ventricular hypertrophy, osteoporosis, and vitiligo. ${ }^{1}$

The common adverse events of statins are arthralgia, myalgia, musculoskeletal pain, muscle spasm, pain in extremities, nausea, diarrhea, dyspepsia, insomnia and pharyngolaryngeal pain. However the most significant adverse events reported are hepatotoxicity, rhabdomyolysis and myocytis. ${ }^{2}$ Recent reports indicate that long-term use and more than moderate dose of statins could cause cognition impairment and impaired glucose tolerance..$^{3-8}$ In 2012, US FDA issued a warning statement that statins might cause fasting hyperglycemia and increased glycated hemoglobin. It is reported that there is $9-13 \%$ increased risk for incident diabetes in patients on statins. And there is a $48 \%$ increased risk of new-onset diabetes in postmenopausal women with statin use. ${ }^{9,10}$ Though US FDA suggested that the cardiovascular benefits of statins outweigh other risks, it is important to study the influence of statin therapy on glycemic status and its preventive measures. 
Sukhija, et al. (2009)analyzed the data of 345,417 patients from the Veterans Affairs database in USA and found that, "Statin use is associated with a rise of fasting plasma glucose (FPG) in patients with and without diabetes. The relationship between statin use and rise in FPG is independent of age and use of aspirin, beta-blockers, and angiotensin-converting enzyme inhibitors". ${ }^{11}$

Goldstein and Mascitelli, in their article titled "do statins cause diabetes?" stated that statins could cause deranged glycemic control by reducing cellular cholesterol levels and disrupting mitochondrial function in pancreatic beta cells, myocytes and adipose tissue. This could affect insulin secretion as well as insulin sensitivity. They also recommended that vitamin D and coenzyme Q could be used along with statin therapy to minimize its influence on glycemic control. ${ }^{12}$

Vitamin D has roles to play in glucose homeostasis and it plays a major role in secretion of insulin. The beta cells of pancreas have vitamin D receptors (VDRs) and 1 hydroxylase enzyme required for conversion of 25-hydroxy vitamin $\mathrm{D}$ to 1, 25 dihydroxy vitamin $\mathrm{D}$. This active form of vitamin D stimulates transcription of insulin receptor gene, peroxisome proliferator activator receptor- $\delta$, expression of insulin receptor, and enhances insulin-mediated glucose transport. ${ }^{13}$

There are conflicting reports on the potential association between statin and vitamin D levels. Few state that vitamin D levels are reduced in patients who are on statin therapy, as cholesterol is the precursor for vitamin $\mathrm{D}$, which may be reduced by statins. ${ }^{14,15}$ Few studies reported that vitamin D levels are increased with statin therapy and it may be due to inhibition of hepatic metabolism of vitamin D by statins. ${ }^{16,17}$

This study aims to investigate the blood sugar changes occur with chronic administration of atorvastatin and the influence of vitamin D on the blood sugar changes in Wistar, albino, and male rats.

\section{METHODS}

The study was initiated after obtaining approval from the Institutional Animal Ethics Committee and conducted in the animal house facility of Chettiand Hospital and Research Institute.

Forty, 12 weeks old male, Wistar albino rats, were selected and randomly allocated to 5 groups of 8 animals, each (Table 1). The animals were fed with commercial pellets chow and water as required and housed at $24 \pm 2^{\circ} \mathrm{C}$ in the animal house. $12 \mathrm{hrs}$ of the day and night cycle was maintained. The animals were acclimatized for a period of 7 days before the study for these conditions (Figure 1).

Animals in Group 1 were administered $1 \mathrm{ml}$ of normal saline with $0.5 \%$ methylcellulose orally and served as controls. Group 2 and 3 received atorvastatin $2 \mathrm{mg}$ and $4 \mathrm{mg}$ respectively, orally. Group 4 and 5 animals received $200 \mathrm{IU}$ of vitamin D along with $2 \mathrm{mg}$ and $4 \mathrm{mg}$ of oral atorvastatin respectively, orally. $0.5 \%$ methylcellulose was used as a vehicle to suspend atorvastatin and vitamin $\mathrm{D}$. The drugs were administered once, every day, for 3 months. The drugs were purchased from authorized vendors along with a certificate of analysis. The doses of atorvastatin were $1 / 10^{\text {th }}$ of the usual adult human doses $20 \mathrm{mg}$ and $40 \mathrm{mg}$. The dose of vitamin D was $1 / 10^{\text {th }}$ or $1 / 20^{\text {th }}$ of the adult human dose of 1000 or 2000 IU.

After randomization into 5 groups, baseline body weight and fasting blood sugar levels were estimated for the animals. Blood sugar was estimated using glucometer (One touch Horizon). These parameters were estimated every month, for 3 months.

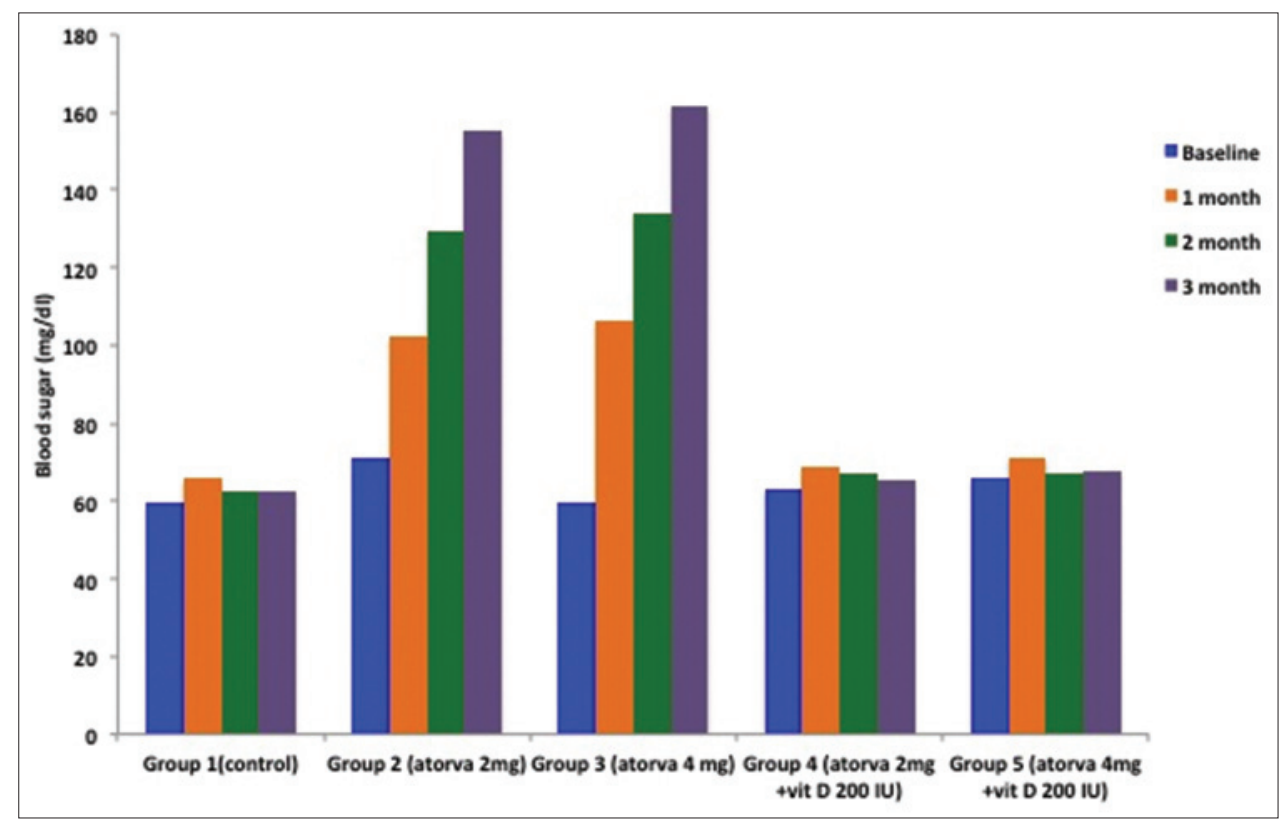

Figure 1: Blood sugar changes. 


\section{RESULTS}

The study was completed as planned without any deviation. There were no adverse events observed in animals and the drugs were well tolerated.

The mean body weight of control animals was $164.12 \pm 10.98 \mathrm{~g}$ before the initiation of the study and it increased significantly to $186.87 \pm 9.17 \mathrm{~g}$ at the end of 3 months. The mean body weight at baseline was 191.37 \pm 21.24 and $203.62 \pm 11.75 \mathrm{~g}$ in atorvastatin 2 and $4 \mathrm{mg}$ groups (Group $2 \& 3$ ), respectively. At the end of the study, it was $199.75 \pm 10.84$, and $186.00 \pm 23.61 \mathrm{~g}$ in atorvastatin 2 and $4 \mathrm{mg}$ groups. The body weight changes in these two groups were not significant. In atorvastatin 2 and $4 \mathrm{mg}$ groups that received 200 IU of vitamin D (Group 4 \& 5), the mean body weight was $171.25 \pm 22.11$ and $176.87 \pm$ $18.84 \mathrm{~g}$ respectively at baseline. After 3 months, the weight increased to $215.50 \pm 41.15$ and $227.00 \pm 34.80$ in the respective groups. The body weight changes in Group 4 $\& 5$ were statistically significant. The data representing body weight changes are listed in Table 2 .

The mean fasting blood sugar in the control animals was $59.50 \pm 5.26 \mathrm{mg} / \mathrm{ml}$ and at the end of 3 months, it was

Table 1: Study groups and treatments.

\begin{tabular}{|ll|}
\hline $\begin{array}{l}\text { Groups } \\
\text { (8 animals in each group) }\end{array}$ & $\begin{array}{l}\text { Drugs } \\
\text { (oral administration) }\end{array}$ \\
\hline Group 1 & Normal saline 1 ml \\
\hline Group 2 & Atorvastatin 2 mg \\
\hline Group 3 & Atorvastatin $4 \mathrm{mg}$ \\
\hline Group 4 & $\begin{array}{l}\text { Atorvastatin 2 mg+ } \\
\text { Vitamin-D 200 IU }\end{array}$ \\
\hline Group 5 & $\begin{array}{l}\text { Atorvastatin 4 mg+ } \\
\text { Vitamin-D 200 IU }\end{array}$ \\
\hline
\end{tabular}

$62.62 \pm 7.00 \mathrm{mg} / \mathrm{dl}$. The baseline mean fasting blood sugar was $71.37 \pm 4.80$ and $59.62 \pm 7.68 \mathrm{mg} / \mathrm{dl}$ in Group 2 and 3 (atorvastatin $2 \& 4 \mathrm{mg}$ ), respectively. Fasting blood sugar increased to $155.00 \pm 6.11$ and $161.50 \pm 4.10 \mathrm{mg} / \mathrm{dl}$ in these groups at the end of 3 months. The increase was statistically significant with the $\mathrm{p}$ value of 0.000 . In Group 4 and 5 (atorvastatin 2 and $4 \mathrm{mg}$ with vitamin D $200 \mathrm{IU}$ ), the mean fasting blood sugar was $63.25 \pm 5.54$ and $65.87 \pm 11.63 \mathrm{mg} / \mathrm{dl}$ respectively at baseline. The values remained at $65.50 \pm 4.37$ and $67.62 \pm 6.54 \mathrm{mg} / \mathrm{dl}$ in these groups after 3 months. The blood sugar changes observed in Group 4 and 5 were not statistically significant. The blood sugar changes are listed in Table 3.

Statistical analysis for changes in body weight and fasting blood sugar was done by one-way ANOVA and the probability values are presented in Tables 2 and 3 .

\section{DISCUSSION}

In this study, it was observed that atorvastatin administered daily at 2 and $4 \mathrm{mg}$ for 3 months produced statistically significant increase in fasting blood sugar levels. Atorvastatin also affected the body weight, which did not increase significantly within the study duration compared to the animals in the control group.

The animals in-Group 4 and 5 which received 200 IU of vitamin D along with atorvastatin 2 and $4 \mathrm{mg}$ did not show significant changes in the blood sugar levels. The blood sugar levels remained at baseline levels after 3 months. The body weight increased like the animals in the control group.

There is no randomized controlled study conducted to investigate the hyperglycemic activity of long-term statin use, though post hoc analysis of published trials had identified this potential risk. Goldstein and Mascitelli,

Table 2: Body weight of animals (in grams).

\begin{tabular}{|llllll|}
\hline Group & 0 day & 1 months & 2 months & 3 months & P value \\
\hline Normal saline & $164.12 \pm 10.98$ & $167.50 \pm 9.57$ & $177.87 \pm 8.27$ & $186.87 \pm 9.17$ & 0.000 \\
\hline Atorvastatin 2 mg & $191.37 \pm 21.24$ & $217.50 \pm 19.94$ & $216.50 \pm 35.80$ & $199.75 \pm 10.84$ & 0.094 \\
\hline Atorvastatin 4 mg & $203.62 \pm 11.75$ & $217.62 \pm 24.58$ & $205.75 \pm 26.78$ & $186.00 \pm 23.61$ & 0.065 \\
\hline Atorvastatin 2 mg+Vitamin-D 200 IU & $171.25 \pm 22.11$ & $187.75 \pm 33.31$ & $206.62 \pm 44.13$ & $215.50 \pm 41.15$ & 0.015 \\
\hline Atorvastatin 4 mg+Vitamin-D 200 IU & $176.87 \pm 18.84$ & $193.00 \pm 31.22$ & $205.25 \pm 41.74$ & $227.00 \pm 34.80$ & 0.034 \\
\hline
\end{tabular}

Table 3: Blood sugar changes (mg/dl).

\begin{tabular}{|llllll|}
\hline Group & 0 day & 1 month & 2 months & 3 months & P value \\
\hline Normal saline & $59.50 \pm 5.26$ & $65.75 \pm 3.91$ & $62.62 \pm 3.24$ & $62.62 \pm 7.00$ & 0.133 \\
\hline Atorvastatin 2 mg & $71.37 \pm 4.80$ & $102.37 \pm 3.81$ & $129.50 \pm 4.37$ & $155.00 \pm 6.11$ & 0.000 \\
\hline Atorvastatin 4 mg & $59.62 \pm 7.68$ & $106.37 \pm 4.50$ & $133.75 \pm 4.49$ & $161.50 \pm 4.10$ & 0.000 \\
\hline Atorvastatin 2 mg+Vitamin-D 200 IU & $63.25 \pm 5.54$ & $68.87 \pm 9.09$ & $67.12 \pm 5.08$ & $65.50 \pm 4.37$ & 0.343 \\
\hline Atorvastatin 4 mg+Vitamin-D 200 IU & $65.87 \pm 11.63$ & $71.37 \pm 6.98$ & $67.37 \pm 5.60$ & $67.62 \pm 6.54$ & 0.573 \\
\hline
\end{tabular}


stated that many drugs used in cardiovascular disorders had the potential to cause hyperglycemia such as thiazides and beta-blockers, besides statins. Even then, these drugs are indicated if the cardiovascular benefits outweigh the hyperglycemic risks. But there is no long-term data available for these drugs, on the glycemic outcomes and complications. ${ }^{12}$

In the "prospective study of pravastatin in the elderly at risk" trial, it was identified that pravastatin treated patients had 30\% more chances of getting new onset diabetes mellitus. ${ }^{18}$ The "justification for use of statins in prevention: an intervention trial evaluating rosuvastatin", revealed that subjects who received rosuvastatin $20 \mathrm{mg}$ daily over the period of 1.9 years, developed significantly higher incidence of type 2 diabetes. However, the cardiovascular benefits outweighed the diabetic risk in that trial. ${ }^{19}$

Goldstein and Mascitelli, are of the opinion that statin therapy increases new-onset diabetes in middle-aged men by 1-2 cases and in the elderly and women by 5-6 cases for every 1,000 subjects treated for a year. The risk is particularly more in Asian population. ${ }^{12}$ Hazard ratios for the development of new onset diabetes in patients receiving statins was calculated in a study of pharmacy database analysis. The analysis included 1,235,671 individuals who received medicines from January 2001 through January 2009. The hazard ratios were 1.42 for rosuvastatin, 1.25 for atorvastatin, 1.14 for simvastatin and 1.02 for pravastatin. This study revealed that the diabetogenic potential of statins could be a drug-class effect. $^{20}$

Statins might cause hyperglycemia through many mechanisms such as impairment of pancreatic beta cell secretory function, myocyte insulin sensitivity, adipocyte insulin sensitivity, mitochondrial function, skeletal muscle function, and exercise tolerance. These factors could affect the insulin secreting potential of beta cells of pancreas as well as insulin sensitivity of target cells. Women and elderly patients are more vulnerable than others for statin induced hyperglycemia. ${ }^{12}$

Vitamin D deficiency is reported to be prevalent in developed countries like $\mathrm{USA}^{21}$ and tropical countries like India. ${ }^{22}$ Studies from different parts of India have suggested that vitamin D deficiency is prevalent in both genders and all age groups of rural and urban areas. The possible reasons could be skin complexion, poor sun exposure, vegetarian food habits and lack of vitamin D food fortification program..$^{22}$

Vitamin D is important for both insulin secretion and its sensitivity in target cells $s^{13,23}$ and there are data indicating that vitamin D is important to maintain the glycemic control. When endogenous vitamin D production is low in winter months possibly due to poor sunlight, the glycemic control is adversely affected compared to tropical months with bright sunlight. ${ }^{24,25}$ It is also reported that individuals who have their daily intake of vitamin D more than 511 IU have a lower incidence of diabetes mellitus when compared to individuals with less than 159 IU.22

Pittas et al. studied 92 diabetic subjects and reported that 700 IU of daily dietary supplementation with vitamin D improved fasting hyperglycemia over a period of 3 years along with $500 \mathrm{mg}$ calcium citrate. ${ }^{26}$ Vitamin D deficient individuals who had insulin resistance, when administered with $4000 \mathrm{IU} /$ day of vitamin D for 6 months, their vitamin $\mathrm{D}$ levels became corrected and at the same time it improved the insulin sensitivity. ${ }^{27}$

Moreover, statin induced adverse events such as myalgia and myositis are prevalent among patients who have vitamin D deficiency compared to patients whose blood levels of vitamin D are normal. ${ }^{28}$ The occurrence of muscle related adverse events could be treated or prevented with the administration of vitamin D. However, vitamin D supplementation to manage statin induced muscle disorders may be effective only in patients with low vitamin D levels and it may not be a remedy to all patients. ${ }^{29}$

The possible mechanisms of improvement in glycemic status when vitamin $\mathrm{D}$ is administered could be the following. ${ }^{22}$

a. Improved $\beta$-cell function - A direct effect of vitamin D or an indirect effect due to increase in the intracellular ionized calcium, which would cause better insulin release

b. Increased insulin sensitivity - It is related to expression of insulin receptor or via calcium dependent pathways in target cells. This increases glucose utilization at a cellular level

c. Inhibition of $\beta$-cells apoptosis - It may be due to VDR transcription factor, which mediates inhibition of cytotoxic cytogene gene expression.

Hence, opinion has emerged that statin induced hyperglycemia could be treated or prevented with vitamin D supplementation, though; there are no well-controlled studies in humans, yet available. And this is in a situation where the relationship between statins and vitamin $\mathrm{D}$ is not very clear on whether the interaction increases the vitamin D levels or decreases.

In the present study, group of animals that received vitamin D along with atorvastatin did not show any difference in the fasting blood glucose levels at the end of treatment compared to baseline fasting blood sugar levels.

The limitations of the study could be that postprandial blood glucose, HbA1C, insulin, c peptide levels and insulin resistance indicators were not estimated and the study is lacking in sufficient information to understand the reasons for the increased blood sugar levels. Vitamin D levels were 
also not estimated and hence whether vitamin D levels were abnormal in atorvastatin only treated animals was not known. In spite of these inadequacies, the study has well established that vitamin D could prevent statin induced fasting hyperglycemia.

\section{CONCLUSION}

This study has demonstrated that chronic use of atorvastatin 2 and $4 \mathrm{mg}$ leads to fasting hyperglycemia and it could be prevented by concomitant administration of $200 \mathrm{IU}$ of vitamin $\mathrm{D}$, in male Wistar albino rats. Randomized control studies for longer duration in animals and humans are further required to recommend the use of vitamin $\mathrm{D}$ in patients receiving atorvastatin.

\section{ACKNOWLEDGMENT}

The authors express their sincere thanks and gratitude to management of Chettinad Hospital and Research Institute for their support in conducting the study.

\section{Funding: None \\ Conflict of interest: None declared \\ Ethical approval: The study was approved by the \\ Institutional Animal Ethics Committee}

\section{REFERENCES}

1. Pella D, Rybar R, Mechirova V. Pleiotropic effects of statins. Acta Cardiol Sin. 2005;21:190-8.

2. Lipitor ${ }^{\circledR}$ Prescribing Information. Pfizer. Distributed by Park Davis. USA. Oct, 2012.

3. While A, Keen L. The effects of statins on mood: a review of the literature. Eur J Cardiovasc Nurs. 2012;11(1):85-96. PubMed PMID: 20875773.

4. Steenland K, Zhao L, Goldstein FC, Levey AI. Statins and cognitive decline in older adults with normal cognition or mild cognitive impairment. J Am Geriatr Soc. 2013;61(9):1449-55. doi: 10.1111/jgs.12414. Epub 2013 Sep 3.

5. Glasser SP, Wadley V, Judd S, Kana B, Prince V, Jenny N, et al. The Association of statin use and statin type on cognitive performance: Analysis of the reasons for geographic and racial differences in stroke (REGARDS)study. Clin Cardiol. 2010;33(5):280-8. doi: 10.1002/clc.20758.

6. Belalcazar LM, Raghavan VA, Ballantyne CM. Tatininduced diabetes: Will it change clinical practice? Diabetes Care. 2009;32(10):1941-3.

7. Preiss D, Sattar N. Statins and the risk of new-onset diabetes: a review of recent evidence. Curr Opin Lipidol. 2011;22(6):460-6. doi: 10.1097/MOL.0b013e32834b4994.

8. Culver AL, Ockene IS, Balasubramanian R, Olendzki BC, Sepavich DM, Wactawski-Wende J, et al. Statin use and risk of diabetes mellitus in postmenopausal women in the Women's Health Initiative. Arch Intern Med. 2012;172(2):144-52. doi: 10.1001/archinternmed.2011.625. Epub 2012 Jan 9.

9. FDA drug safety communication: Important safety label changes to cholesterol-lowering statin drugs. Available from: http://www.fda.gov/Drugs/DrugSafety/ucm293101. htm\#sa. [Last accessed on 2012 Oct 16].

10. Labeling changes to statins address adverse health effects, March 2, 2012. The endocrine society. 8401 Connecticut Avenue, Suite 900 Chevy Chase, Maryland 20815-5817 Telephone 301.941.0200 Fax 301.941.0259. Available from: http://www.endo-society.org.

11. Sukhija R, Prayaga S, Marashdeh M, Bursac Z, Kakar P, Bansal D, et al. Effect of statins on fasting plasma glucose in diabetic and nondiabetic patients. J Investig Med. 2009;57(3):495-9.

12. Goldstein MR, Mascitelli L. Do statins cause diabetes? Curr Diab Rep. 2013;13(3):381-90. DOI 10.1007/s11892-0130368-x.

13. Alvarez JA, Ashraf A. Role of vitamin d in insulin secretion and insulin sensitivity for glucose homeostasis. Int $\mathrm{J}$ Endocrinol. 2010;2010:351385. doi: 10.1155/2010/351385.

14. Pera $Ł$, Sygitowicz G, Białek S, Łukaszkiewicz J, Sitkiewicz D. Vitamin D and statins: action in preventing cardiovascular events. Kardiol Pol. 2012;70, 12: 1296-1298.

15. Eisen A, Lev E, Iakobishvilli Z, Porter A, Brosh D, Hasdai D, et al. Low plasma vitamin d levels and muscle-related adverse effects in statin users. Isr Med Assoc J. 2014;16:42-5.

16. Yavuz B, Ertugrul DT, Cil H, Ata N, Akin KO, Yalcin AA, et al. Increased levels of 25 hydroxyvitamin D and 1,25-dihydroxyvitamin $\mathrm{D}$ after rosuvastatin treatment: a novel pleiotropic effect of statins? Cardiovasc Drugs Ther. 2009;23(4):295-9. doi: 10.1007/s10557-009-6181-8.

17. Aloia JF, Li-Ng M, Pollack S. Statins and vitamin D. Am J Cardiol. 2007;100(8):1329.

18. Sattar N, Preiss D, Murray HM, Welsh P, Buckley BM, de Craen AJM, et al. Statins and risk of incident diabetes: a collaborative meta-analysis of randomized statin trials. Lancet. 2010;375:735-42.

19. Ridker PM, Danielson E, Fonseca FAH, Genest J, Gotto AM, Kastelein JJP, et al. For the JUPITER Study Group. N Engl J Med. 2008;359:2195-207.

20. Zaharan NL, Williams D, Bennet K. Statins and risk of treated incident diabetes in a primary care population. Br J Clin Pharmacol. 2012;75(4):1118-24.

21. Binkley N, Ramamurthy R, Krueger D. Low vitamin D status: definition, prevalence, consequences, and correction. Endocrinol Metab Clin N Am. 2010;39:287-301.

22. Goswami R, Mishra SK, Kochupillai N. Prevalence and potential significance of vitamin D deficiency in Asian Indians. Indian J Med Res. 2008;127:229-38.

23. Andrade Chagas CE, Borges MC, Martini LA, Rogero MM. Focus on vitamin D, inflammation and type 2 diabetes. Nutrients. 2012;4:52-67. doi:10.3390/nu4010052.

24. Ishii H, Suzuki H, Baba T, Nakamura K, Watanabe T. Seasonal variation of glycemic control in type 2 diabetic patients. Diabetes Care. 2001;24:1503.

25. Campbell IT, Jarrett RJ, Keen H. Diurnal and seasonal variation in oral glucose tolerance: studies in the Antarctic. Diabetologia. 1975;11:139-45.

26. Pittas AG, Harris SS, Stark PC, Dawson-Hughes B. The effects of calcium and vitamin D supplementation on blood glucose and markers of inflammation in non-diabetic adults. Diabetes Care. 2007;30:980-6.

27. Von Hurst PR, Stonehouse W, Coad J. Vitamin D supplementation reduces insulin resistance in South Asian women living in New Zealand who are insulin resistant and vitamin D deficient - A randomized, placebo-controlled trial. Br J Nutr. 2010;103:549-55.

28. Ahmed W, Khan N, Glueck CJ, Pandey S, Wang P, 
Goldenberg N, et al. Low serum 25(OH) vitamin D levels $(<32 \mathrm{ng} / \mathrm{mL})$ are associated with reversible myositis-myalgia in statin-treated pa- tients. Transl Res. 2009;153:11-6.

29. Gupta A, Thompson PD. The relationship of vitamin D deficiency to statin myopathy. Atherosclerosis. 2011;215(1):23-9. doi: $10.5455 / 2319-2003 . i j b c p 20140420$

Cite this article as: Arunkumar R, Meti V, Ruckmani A,

Devi S. Effect of vitamin D on atorvastatin induced blood sugar changes in Wistar albino rats. Int J Basic Clin Pharmacol 2014;3:2:359-64. 